Abstracta Iranica Abstracta Iranica

Revue bibliographique pour le domaine irano-aryen

Volume 42-43 | 2021

Comptes rendus des publications de 2019-2020

\title{
Domenico Agostini. "Luhrāsp and the Destruction of Jerusalem: A Note on Jewish-Iranian Syncretism"
}

\section{Florence Somer}

\section{(2) OpenEdition}

1 Journals

\section{Édition électronique}

URL : https://journals.openedition.org/abstractairanica/54251

DOI : 10.4000/abstractairanica.54251

ISSN : 1961-960X

Éditeur :

CNRS (UMR 7528 Mondes iraniens et indiens), Éditions de l'IFRI

\section{Référence électronique}

Florence Somer, « Domenico Agostini. "Luhrāsp and the Destruction of Jerusalem: A Note on JewishIranian Syncretism" », Abstracta Iranica [En ligne], Volume 42-43 | 2021, document 40, mis en ligne le 30 décembre 2021, consulté le 12 décembre 2022. URL : http://journals.openedition.org/ abstractairanica/54251; DOI : https://doi.org/10.4000/abstractairanica.54251

Ce document a été généré automatiquement le 12 décembre 2022.

Tous droits réservés 
Domenico Agostini. "Luhrāsp and the Destruction of Jerusalem: A Note on Jewish-Iranian Syncretism"

Florence Somer 


\section{RÉFÉRENCE}

Domenico Agostini. "Luhrāsp and the Destruction of Jerusalem: A Note on JewishIranian Syncretism" in Julia Rubanovich, Geoffrey Herman (eds.). Irano-Judaica VII.

Studies Relating to Jewish Contacts with Persian Culture throughout the Ages. Jerusalem: BenZvi Institute for the Study of Jewish Communities in the East, 2019, p. 297-309

1 Dans le cadre de l'interrogation de l'historicité des sources de textes en moyen-perse écrits ou recopiés à l'époque islamique, l'A. s'intéresse à une histoire dont le titre même traduit le syncrétisme. La figure du roi kayanide Luhrāsp n'est pas commune dans la littérature avestique et moyen-perse. Il n'apparaît pas dans la liste des rois dressée dans les Yašts 13 et 19. Par contre, sa figure est présente dans la littérature plus tardive : dans le Bundahišn (34:14,35:34, 35, 36:7), le Dēnkard, le Dādestān ì mēnōg ì xrad ainsi que le Shāh-nāma. Il semble que ce roi fonctionne en tant que palliatif au vide existant dans la tradition légendaire entre le règne de Kay Husrau et de Guštāsp. Sa présence dans les textes en moyen-perse semble être le résultat d'une interpolation qui fait de Luhrāsp le destructeur de Jérusalem. Dans le prologue du Denkārd, Ādurfarrobay raconte que la destruction de Jérusalem s'est faite par l'entremise de Bōxt-Narsēh (Bukhtrašah ou Nabuchodonosor), version qui est amplifiée dans la littérature islamique, ce qui permet à l'A. de déduire des éléments pour comprendre la formation et la transmission de ce syncrétisme irano-juif. La question de l'effectivité de cette transmission est évidemment centrale. Le troisième livre du Dēnkard montre des éléments pointant vers l'époque sassanide, non à l'époque islamique, particulièrement durant la conquête de Hुusrau II en 614.

\section{AUTEURS}

\section{FLORENCE SOMER}

Doctorante EPHE, CeRMI, Paris 